\title{
Peer Review System: Any Other Choice?
}

\author{
Yataro Yoshida \\ Takeda General Hospital, Kyoto, Japan
}

Int J Hematol. 2006;83:191-192. doi: 10.1532/IJH97.06031

(C)2006 The Japanese Society of Hematology

The whole world was shaken at the revelation that South Korean researcher Professor Woo Suk Hwang had been involved in falsifying data in 2 seminal papers published in Science. Following an official report by a search committee at Seoul National University that Professor Hwang and his colleagues fabricated much of the data in both papers, the editors of Science decided to retract these 2 papers [1]. Thus is lost the hope that cloned embryos could produce embryonic stem cells tailor-made to match a patient's DNA. I am not going to discuss what drove him to such scientific misconduct. Suffice it to say that the action of Science has resulted in reverberations in other journals that in the past have published some data from Professor Hwang's group. For instance, the journal Stem Cells expressed concern over an apparent duplication of images within a paper published in Stem Cells in 2004 as well as use of an image appearing in the 2004 Science paper [2].

At first, I felt very disappointed to know that these fabricated papers eluded peer reviewing in top scientific journals such as Science, because peer review in my mind is the cornerstone of editorial policies worldwide. However, as I thought it over, I came to realize that it might not be easy to detect fraudulent articles if the fraud is carefully planned. My own experience as author, referee, and editor indicates that peer review is regarded as the gold standard of modern science. For us scientists, it is the essential gateway to funding, publication, and career advancement. Clearly, we are judged largely by peer-reviewed publications when we apply for research grants, new jobs, or even tenure.

Scientists compete with each other for space to publish in the most prestigious and most widely read journals. Space is allocated by editors, and peer review plays a big part in the process. Every paper is carefully read by experts who check the accuracy of the material, suggest improvements, and advise the editor about the overall quality. The saying "publish or perish" tells how heavily publication is

Correspondence and reprint requests: Yataro Yoshida, MD, Former Editor-in-Chief, Director, Takeda General Hospital, 28-1 Ishida-Moriminami, Fushimi-ku, Kyoto 601-1495, Japan (e-mail: yoshida@takedahp.or.jp). weighed in any field of science. Peer review has been the traditional mechanism to filter out lousy papers, faulty experiments, and irrelevant findings [3]. Scientists submit their work to qualified journals for publication, the editors of which in turn select specialists as referees to advise them within a limited period of time as to whether the material has potentially new findings and, if so, whether further work is needed to make it publishable. A paper is only accepted when the requisite revisions are made to the approval of both the editor and referees. The process is intended to ensure that any study's methodology is sound and that interpretation of data does not go beyond what can be reasonably justified.

This time-honored system, however, is far from foolproof. Editors can bias the referee selection. In addition, although a reviewer can check the accuracy of the paper, he cannot repeat the experiment. Hence, his or her review may often be more or less a comment on whether the research appears to be well done. Disagreement among reviewers is not uncommon and is a reflection of the complexity of the process of manuscript evaluation. Peer review in its current system is not designed to detect fraud if it is artfully done, as were the 2 papers published in Science [4]. Extra caution is needed for publishing research designed just to grab headlines in the mainstream media. Clearly there is a quality hierarchy among journals, based on the stringency of their peer review and the threshold of acceptance, all the way down to an unrefereed periodical at the bottom. Persistent authors can work their way down until their paper finds its own level. In fact, reviewers not infrequently find themselves called upon more than once to review the same paper, sometimes unchanged, for several different journals. By contrast, journals with high impact factors want to publish articles containing the "firsts." By definition, "firsts" haven't been replicated, thus reviewing could be looser and riskier.

Peer review doesn't necessarily say that a paper is right, it says it's worth publishing. As mentioned above, peer review often overlooks honest errors as well as deliberate fraud. Of interest is an example of a test in which British Medical Journal editors inserted 8 errors into a short paper and asked researchers to identify them. Very few were able to spot all of the errors, if any [4]. Image manipulation and fake DNA data 
are not the sort of things reviewers can easily spot. Independent analysis of images by enlarging and scrutiny in papers near acceptance may be of some help. This policy has been adopted in certain journals including the Journal of Cell Biology. Ideally, a team of well-trained, full-time editors and professional statisticians might be able to carry on the functions of peer review on their own, but such a team is too good to be realistic.

Given the limitations of peer review, what can be done to improve the quality of reviewing? The Journal of the American Medical Association and some other journals advocate the policy that all coauthors detail their contributions to the paper. It may be administratively complex, but if the paper is wrong, everyone takes the fall equally and sees who is largely responsible for the reviewers' criticism. Another argument centers on selection of referees, blind reviewers versus author-suggested reviewers [5]. Authors may be in a better position than editors to know who is best qualified to evaluate their findings, and they may have valid reasons for keeping sensitive results out of the hands of a close competitor. This open review system may look sound against the criticism for blind reviewing being too secretive, conducted behind closed doors and assessed by anonymous referees. Two studies compared editor-chosen versus authorsuggested reviewers, and found no significant difference in the quality or timeliness of reviews. But both studies indicated that author-suggested reviewers were more likely to recommend publication and less likely to recommend rejection. Obviously, like the process in jury selection in the court, many personal factors come into play in many ways. The identities of reviewers apparently have no effect on the quality of peer review.
Open access in recent years to electronic communication has intensified the existing skepticism about the value of peer review system. Online publication permits researchers to post their work without prepublication peer review. This system seems to be working well in physical science, but we cannot dismiss the problem of quality control in electronic publication in the field of life science. Especially in medical journals, we have to provide scientifically correct information, thus leaving few chances for online publication to replace peer reviewed journals. The question is not of dispensing with peer review, but of how we can best measure its quality.

Undoubtedly, the peer review system does not satisfy everyone, but if peer review didn't work, it would be an extraordinary waste of time. Let me finish by citing the statement "despite its limitations, we need it. It is all we have, and it is hard to imagine how we could get along without it" [6].

\section{References}

1. Kennedy D. Editorial retraction. Science. 2006;311:335.

2. Civin C. Cloned photomicrographs, not cloned cells. Stem Cells. 2005 Dec 28 [Epub ahead of print].

3. Harnad S. Rational disagreement in peer review. Sci Technol Human Values. 1985;10:55-62.

4. Couzin J. Stem cells. ... and how the problems eluded peer reviewers and editors. Science. 2006;311:23-24.

5. Grimm D. Suggesting or excluding reviewers can help get your paper published. Science. 2005;309:1974.

6. Laine $\mathrm{C}$, Mulrow C. Peer review: integral to science and indispensable to annals. Ann Intern Med. 2003;139:1038-1040. 